\title{
Depression, anxiety, and burnout among medical students and residents of a medical school in Nepal: a cross-sectional study
}

\author{
Nishan Babu Pokhrel ${ }^{1 *}$ (D, Ramesh Khadayat ${ }^{1}$ and Pratikchya Tulachan ${ }^{2}$
}

\begin{abstract}
Background: Medical students and residents were found to have suffered from depression, anxiety, and burnout in various studies. However, these entities have not been adequately explored in the context of Nepal. We proposed to determine the prevalence of depression, anxiety, burnout, their associated factors, and identify their predictors in a sample of medical students and residents in a Nepalese medical school.
\end{abstract}

Methods: It was a cross-sectional study with 651 medical students and residents chosen at random between December 2018 and February 2019. The validated Nepali version of Hospital Anxiety and Depression Scale, the Copenhagen Burnout Inventory, and Medical Students' Stressor Questionnaire were used to assess depression, anxiety, burnout, and stressors respectively. We used univariate and multivariable logistic regression analyses to identify the correlation of predictor variables with depression, anxiety, and burnout.

Results: The overall prevalence of burnout $(48.8 \%$; $95 \% \mathrm{Cl} 44.9-52.7)$ and anxiety $(45.3 \%$; $95 \% \mathrm{Cl} 41.4-49.2)$ was more than that of depression $(31 \% ; 95 \% \mathrm{Cl} 27.5-34.7)$. Burnout and depression were more prevalent in residents than in medical students (burnout: 64.5\% vs 37.6\%, $P$-value < 0.0001 ; depression: $33.7 \%$ vs $29.1 \%, P$-value 0.21 ). Whereas, medical students were found more anxious than residents (46.3\% versus $43.96 \%, P$-value 0.55$)$. Academic related stressors caused high-grade stress to participants. Multivariable model for depression significantly showed anxiety, personal burnout, and work-related burnout as risk enhancing correlates; satisfaction with academic performance as a protective correlate. Similarly, the multivariate model for anxiety significantly identified female gender, depression, personal burnout, teaching and learning related stressors, and past history of mental illness as risk enhancing correlates; being satisfied with academic performance, getting adequate sleep, and being a secondyear resident as protective correlates. The logistic model for burnout significantly showed being a first-year resident, depression, anxiety, and drive and desire related stressors as positive predictors. None of the variables were identified as significant negative predictors of burnout.

(Continued on next page)

\footnotetext{
* Correspondence: nishanpokhrel1@iom.edu.np

${ }^{1}$ Tribhuvan University Institute of Medicine, Kathmandu, Nepal

Full list of author information is available at the end of the article
}

(c) The Author(s). 2020 Open Access This article is licensed under a Creative Commons Attribution 4.0 International License, which permits use, sharing, adaptation, distribution and reproduction in any medium or format, as long as you give appropriate credit to the original author(s) and the source, provide a link to the Creative Commons licence, and indicate if changes were made. The images or other third party material in this article are included in the article's Creative Commons licence, unless indicated otherwise in a credit line to the material. If material is not included in the article's Creative Commons licence and your intended use is not permitted by statutory regulation or exceeds the permitted use, you will need to obtain permission directly from the copyright holder. To view a copy of this licence, visit http://creativecommons.org/licenses/by/4.0/ The Creative Commons Public Domain Dedication waiver (http://creativecommons.org/publicdomain/zero/1.0/) applies to the data made available in this article, unless otherwise stated in a credit line to the data. 
(Continued from previous page)

Conclusions: A high prevalence of depression, anxiety, and burnout was seen among medical students and residents. Most of them were stressed with academic-related factors. A strong correlation between teaching and learning-related stressors with depression and anxiety may be a call for an efficient and more student-friendly curriculum.

Keywords: Anxiety, Burnout, Depression, Developing countries, Medical students, Residents, Stressors, South Asia

\section{Background}

Medical education is long, and physically and emotionally demanding. Before entering into the medical school, the mental health of medical students is similar to that of the general population [1-3] or even better [4]. Inside the medical school, they are exposed to various academic and psychosocial stressors [5] thought to be typical of the medical school environment. They are exposed to workload [6-8], academic pressure [9], the need to be seen as a competent clinician [10], sleep deprivation [7], peer competition [7], fear of failure in medical school [7], death and suffering of patient [11], student abuse [12], financial problem [7, 8], etc. In addition to these, they also face personal life events, which are beyond the control of medical school authority like illness, marriage, the birth of a child, and death of family members. Due to the aforementioned stressful events, the mental health of medical students declines as they progress in their medical training $[2,6,13]$. The decline starts right from their first year [14]. These stressors result in their poor academic performance, academic dishonesty, cynicism, substance abuse [15], and serious mental illnesses like depression, anxiety, and burnout. The poor health-related quality of life among medical students is contributed mainly by the mental component [16].

The data regarding the status of mental health among Nepalese medical students and residents are sparse, as enough studies have not been conducted here. A few studies on the prevalence of anxiety and depressive disorders among medical students have been done in Nepal which revealed a high prevalence of anxiety and depressive disorders [17-20]. In developing nations like Nepal, medicine is not only looked upon as a career, but also as an opportunity for social advancement. This may result in increased pressure to students as compared to their counterparts in developed nations [21].

Burnout is defined as a psychological syndrome of emotional exhaustion, depersonalization, and reduced personal accomplishment induced by repeated exposure to workplace stressors [22]. Emotional exhaustion is the feeling of extreme fatigue with draining of emotional resources due to repeated exposure to workplace stressors. Depersonalization is the distant attitude towards the job in which the person attempts to keep a distance between oneself and the clients. Reduced personal efficacy implies a feeling of being ineffective in the work accompanied by the feeling of low self-esteem [23]. The components of burnout can also be grouped as personal burnout, work-related burnout, and client-related burnout [24]. Personal burnout [24] refers to the degree of physical and psychological fatigue experienced by the person regardless of his/her work. Work-related burnout [24] refers to the degree of physical and psychological fatigue perceived by the person as related to his/her work. Client-related burnout [24] refers to the fatigue-related to interaction with clients.

Burnout in healthcare workers is a universal concern [25]. Different studies across the world have shown a high prevalence of burnout among medical students [21, 26,27 ] and residents [28]. Burnout is found to be prevalent among medical students even prior to the initiation of the clinical years of medical training $[29,30]$. It then progressively develops over the course of medical training [31]. A recent meta-analysis has found a high prevalence of burnout in medical and surgical residents [32]. Various factors predict the likelihood of burnout in physicians which are job dissatisfaction [33], huge work intensity, and lack of time off [33]. Physician burnout is linked with an increase in medical errors [34] and reduced quality of patient care [35]. Burnout also increases the risk of suicidal ideation $[27,36]$. Burnout is significantly associated with state-anxiety [37] and depression $[38,39]$. Neglected burnout also results in other serious consequences such as substance abuse, depression, insomnia, and impaired interpersonal and marital relationship [40].

About a third of medical students in the world suffer from depression [41] which is much higher than the general population (about 3.9-6.6\%) [42, 43] and nonmedical students ( $19 \%$ in men, $22 \%$ in women) [44]. A higher level of depression was reported in first-year residents as well [45]. Depression is found to be significantly associated with chronic sleep deprivation [45], stressful personal life events, and burnout [46]. Burnout and depressive symptoms significantly predicted serious thoughts of dropping out of the medical school [47]. Interestingly, burnout has been described as a form of depression [48]. Burnout and depression have their etiological association with repeated and unresolvable stress. 
Unresolvable stress has been described as causing depression as well [49].

The prevalence of depression in Nepalese medical students was found to be around $30 \%$ and was consistent across all four studies [17-20]. The prevalence of anxiety was found to be around 5.8\% [18]. Adhikari et al. [18] attempted to widen the focus into the study of depression, anxiety, suicidal ideation, marijuana use, smoking, and eating disorders while other studies were focused on depression [17, 19, 20], suicidal ideation [50], anxiety disorders [19], and stressors [5]. None of them included residents in their study and none studied the prevalence of burnout either.

Hence, we planned this study to determine the prevalence of depression, anxiety, burnout and their associated factors, and identify their predictors among medical students and residents of a Nepalese medical school.

\section{Methods}

\section{Study design, setting, and participants}

We carried out a descriptive cross-sectional study between December 2018 and February 2019 in Maharajgunj Medical Campus (MMC) located in Kathmandu, Nepal. All the medical students and residents who had spent at least a year in the medical school were considered eligible for the study. Students who were not available during the data collection period were excluded from the study.

\section{Sample size and sample procedure}

Simple random sampling based on the lottery method was carried out to select the participants. The sample size was calculated using the formula:

$$
n=\frac{Z^{2} p(1-p)}{E^{2}}
$$

where, $n=$ minimum sample size when population is large, $Z=$ confidence level at $95 \%$ (standard value of 1.96), $p$ = prevalence (taken 0.30 based on $29.9 \%$ prevalence of depression in a similar Nepalese study [19]), $E=$ allowable error $(5 \%$ of $p$ ). For finite population: $n$ finite $=\frac{n}{1+\frac{n}{N}}$,

where $n=$ calculated initial sample size using the previous formula, which was 3585 and $N=$ finite population number (the total number of medical students and residents of our medical school $=732$ ).

$$
n \text { finite }=\frac{3585}{1+\frac{3585}{732}}, n \text { finite }=608 \text {. }
$$

After considering the proportion $(q)$ that was expected to refuse to participate or provide inadequate information, the final number of samples to be recruited was

$$
n^{*}=\frac{n}{1-q}
$$

Where $q$ is the proportion of attrition and was taken as $10 \%$. After adjusting for the number of nonresponses, the final number of samples was 676 .

\section{Outcome variables}

Depression, anxiety, and burnout were classified as the outcome variables. Depression and anxiety were assessed by using the validated Nepali version of Hospital Anxiety and Depression Scale (HADS) [51] which consists of two subscales: namely an anxiety scale (HADS-A) and a depression scale (HADS-D) each with seven items. As an example, the characteristic items are: "I feel tensed or 'wound up", "I can laugh and see the funny side of things", "I have lost interest in my appearance". All 14 items were rated along a four-point Likert scale according to responses of frequency from zero to three. By adding these up, a sum value for the two scales was obtained. Values from 0 to 7 were considered as normal, 8 to 10 as borderline, and between 11 to 21 as suspicious [52]. In our study, we classified both the borderline and the suspicious groups as having depression. In the same way, we classified the participants as having anxiety and not having anxiety. The internal consistency of the Nepali version of HADS was satisfactory (HADS-A $\alpha=0.76$ and HADS-D $\alpha=0.68$ ) [51]. In the current study, the Cronbach's alpha reliability coefficient was good (HADS-A $\alpha=0.74$ and HADS-D $\alpha=0.73$ ).

Burnout was assessed by using Copenhagen Burnout Inventory (CBI) [24] consisting of three sub-scales measuring specifically personal burnout (6 items), workrelated burnout (7 items), and client-related burnout (6 items). We changed the term 'client' into 'patient'; 'work' into 'work/study', and accordingly replaced them in the questionnaire. So, 'client-related' burnout became 'patient-related' burnout, and 'work-related' burnout became 'work/study-related' burnout. Twelve items were rated along a five-point Likert scale according to responses of frequency from '100 (always)' to '0 (never/almost never)'. The remaining seven items, however, rate the response according to an intensity which ranges from 'to a very low degree' to 'to a very high degree' [24]. But, an item in the work-related burnout subscale required inverse scoring and the item was: "do you have enough energy for family and friends during leisure time?" Typically, items in the scale were: "how often do you feel worn out?", "do you feel burnt out because of your work?", "do you find it hard to work with patients?”. The level of burnout was classified according to the scores obtained. A score of zero to 50 implies "no/low", 50 to 74 implies "moderate', 75 to 99 implies 'high', and a score of 100 implies 'severe' burnout. All the items had 
high internal consistency, and were straightforward and related to the relevant subscale. In our study, the Cronbach's alpha reliability coefficients of the three CBI subscales were high (personal burnout $\alpha=0.79$; workrelated burnout $\alpha=0.87$; and patient-related burnout $=$ 0.85). Burnout was defined if any one of the personal, work-related or patient-related burnout was present in a student.

\section{Independent variables \\ Socio-demographic factors}

Socio-demographic factors included age, gender, religion, nationality, socioeconomic class, current residence, and the year of training in medical school. The variable 'age' was grouped into four age-groups starting from 18 years with increments of 5 years (group $1=18-24$ years, group $2=25-29$ years, group $3=30-34$ years, group $4=$ $35-39$ years). The socioeconomic class was measured using the modified Kuppuswamy's Socioeconomic Status scale in the context of Nepal [53]. The scale consisted of three criteria namely educational, occupational, and economic (monthly family income) based on which a score was given. According to the sum of these three scores, the socioeconomic class was determined according to the classification $(26-29=$ Upper, $16-25=$ Upper middle, 11-15 = Lower middle, $\quad 5-10=$ Upper Lower,$\quad<5=$ Lower).

\section{Behavioral and clinical factors}

Behavioral factors included relationship status, substance use, involvement in extracurricular activities, and sleep hours. Substance use by a person was defined when he/ she uses either alcohol, cigarette, or marijuana. The variable 'sleep hours' was divided into two groups: adequate sleep and inadequate sleep by using a cut-off of $7 \mathrm{~h}$ [54]. Clinical factors included stressors, satisfaction with career choice, satisfaction with academic performance, previous history of mental health problems, family history of mental health problems, and current treatment regarding mental health issues.

The stressors were identified by using the Medical Students' Stressor Questionnaire-20 (MSSQ-20) [55]. MSSQ-20 consisted of 20 items representing the six stressor domains which were: academic related stressors (ARS), intrapersonal and interpersonal related stressors (IRS), teaching and learning-related stressors (TLRS), social related stressors (SRS), drive and desire related stressors (DRS), and group activities related stressors (GARS). All 20 items were rated along a five-point Likert scale according to the intensity from 'zero (causing no stress at all)' to 'four (causing severe stress)'. The mean score of each of the domain was calculated, and thus the severity of the stress caused by that domain was assessed according to the classification (0-1= Mild, 1.01-2=
Moderate, 2.01-3= High and 3.01-4= Severe). Highgrade score in a particular stressor group indicated that it caused a lot of stress, disturbed emotions, and mildly compromised daily activities. It was a valid and reliable instrument with high internal consistency as shown by Cronbach's alpha coefficient value of 0.95 . In the current study, the reliability coefficient was high $(\alpha=0.91)$. The Cronbach's alpha for each stressor domain was also high (ARS $\alpha=0.87$, IRS $\alpha=0.89$, TLRS $\alpha=0.77$, SRS $\alpha=0.74$, DRS $\alpha=0.70$, GARS $\alpha=0.76$ ). Each of the stressors ARS, IRS, TLRS, SRS, DRS, and GARS was grouped into two groups: 'absent' and 'present'. The 'absent' group included those participants who felt only the mild form of those stressors while the 'present' group included all other participants feeling the moderate, severe, and high degree of those stressors.

\section{Methods of data collection}

For the purpose of data collection, the aim of the study was briefly described, and doubts of the participants regarding the study were cleared by the investigators. Participants were requested to choose the item in the questionnaire that was closest to what they have been feeling in the past week, to minimize recall bias. Following this, the questionnaire form was distributed to them. Questionnaire form contained questions regarding socio-demographic, behavioral, and clinical characteristics of the participants along with the scales for measuring depression, anxiety, burnout, and stressors in the participants. We used reliable and validated instruments to minimize information bias. Our survey questionnaire is provided as an Additional file 1 .

\section{Statistical analysis}

$\mathrm{R}$ software (version 3.5.3) [56] and various $\mathrm{R}$ packages were used for statistical analyses. 'G-models' package [57] was used to construct a cross-table, 'caret' [58] and 'caTools' package [59] for multivariable logistic regression analyses, 'rcompanion' [60] for calculating Cox and Snell, and Nagelkerke pseudo R squared, 'Imtest' [61] for likelihood ratio test, 'ROCR' [62] and 'Metrics' [63] for calculating AUC and plotting ROC curve, 'ResourceSelection' [64] for Hosmer Lemeshow test, 'survey' [65] for Wald test, 'corrplot' [66] for plotting the contingency table, and 'ggplot' [67] for making bar plots.

A total number of 43 variables (numerical-34, categorical-9) from 19 observations were missed. The missing data in a numerical variable were replaced by averages and that of a categorical variable by modes. Descriptive statistics were used for sociodemographic, behavioral, and clinical variables. We used an alpha level of 0.05 as a cut-off point for statistical significance. Univariate analysis was used to find the association of depression, anxiety, and burnout with independent 
variables. The multivariable logistic regression analysis was used to determine the predictors of depression, anxiety, and burnout. We tested for multicollinearity by calculating variance inflation factor (VIF) score for each variable in the predictor models using the "vif" function of "car" package [68]. We set the cut-off VIF score of 10 and found two variables ("age" and "year") having higher VIF scores. Thus, we removed a variable ("age") and rechecked for the collinearity among the remaining variables. As we found no correlation among the remaining variables, we reconstructed the logistic models using the variables except "age". The stepwise logistic regression using backward elimination method was performed using $\mathrm{R}$ software. The scripts used while preparing these models in $\mathrm{R}$ software will be available from the author upon reasonable request.

The model with the lowest AIC (Akaike Information Criterion) value was selected as the best-fitted model. Likelihood ratio test and Hosmer-Lemeshow tests were done to test for the goodness of fit of the model. The Cox and Snell, and Nagelkerke pseudo R squared represented the proportion of variance in the outcome variable that was explained by the variables in the model. Tests of individual predictors were done to assess the relative importance of those variables in the model, like Variable Importance using 'caret' package [58] and Wald test using 'survey' package [65]. Validation of predicted values was done by constructing ROC curve using 'ROCR' [62] and 'Metrics' [63] packages.

\section{Ethical considerations}

Ethical clearance was obtained from the Institutional Review Committee of the Institute of Medicine (Reference number-305/075/076). A cover letter consisting of informed consent was attached with each questionnaire, which included a description of the study and participants' rights to decline altogether or to leave the questions answered. The consent was implied through the completion of the questionnaire. The name, address, or signature of the participant were not included in the questionnaire to keep the identity of the participant anonymous. Participants did not receive any incentives or financial compensation for participating in the study.

\section{Results}

\section{Participants}

The total number of medical students and residents studying in the Maharajgunj Medical Campus was 732 . The calculated sample size required for the study with an allowable error of $5 \%$ of $p$ was 676 . A total of 651 students returned the questionnaire form with a nonresponse rate of $3.7 \%$. Among them, 495 (76\%) were males and 156 (24\%) were females. The third-year medical students had the highest participation (71 out of 77 ,
93.4\%) whereas, the interns had the lowest (47 out of 60 , $78.3 \%)$. Interns were those medical students who passed their final year and were doing an internship. Similarly, first-year residents had greater participants, 97 (14.9\%) compared to second and third-year residents.

\section{Characteristics of study participants}

The socio-demographic profile of the participants is presented in Table 1 . The mean age was 25 years. Most of the participants belonged to the age category $18-24$ years $(314,48.2 \%)$, whereas only 4 $(0.6 \%)$ participants were over 35 years of age. Most of the participants were Hindu (611, 93.9\%). The number of Nepalese participants was 566 (86.9\%); remaining others were Indian, Sri Lankan, and Maldivian. Majority of the participants were single (392, $60.3 \%)$ and only $135(20.8 \%)$ were married. Most of the participants belonged to upper-middle socioeconomic class (302, 46.5\%), followed by upper (215, $33.1 \%)$, lower-middle $(121,18.6 \%)$, and upper-lower (11, 1.7\%) socio-economic classes. Only a single participant was residing in the hospital quarter, while a majority $(240,36.9 \%)$ were living in rented rooms.

Table 2 summarizes the behavioral and clinical characteristics of the participants. The number of participants having the thoughts of suicide and thoughts of dropping out of medical school were 41 (6.3\%) and $79(12.1 \%)$ respectively. Similarly, 35 (5.4\%) participants had a previous history of mental disorders, $5(0.8 \%)$ were currently receiving treatment for mental illnesses, and 55 (8.4\%) participants had a family history of mental problems. Participants usually slept for an average of $7 \mathrm{~h}$. The number of participants who were not satisfied with their career choice was 145 (22.31\%). A large number of participants, 307 (47.23\%) were not satisfied with their academic performance. Only 221 (34\%) of participants were involved in extracurricular activities. The number of participants who drank alcohol, smoked cigarettes, or smoked marijuana was 393 (60.4\%), 241 (37.1\%), and $100(15.4 \%)$ respectively. Substance use was found in 398 (61.1\%) of participants.

Depressive features were seen in 202 (31\%) participants, and the features of anxiety were found in 295 (45.3\%) participants. A huge number $(318,48.8 \%)$ of participants suffered at least one of personal, work-related, or patient-related burnout with greater proportion, 266 (40.8\%) of them suffering from personal burnout. Mean scores on the HADS-A, HADS-D, CBI-Personal, CBIWork/study, and CBI-Patient subscales were 7.39 (standard error of the mean $S E=0.13), 6.08(S E=0.14), 47.93$ $(S E=0.66), 42.61(S E=0.72)$, and $35.02(S E=0.75)$ respectively. Figure 1 compares the prevalence of depression, anxiety, and burnout by years of training of participants. 
Table 1 Socio-demographic profile of the participants, $N=651$

\begin{tabular}{|c|c|}
\hline Socio-demographic features & $n,(\%)$ \\
\hline Male & $495(76)$ \\
\hline Mean age $(S D)$ & $25(4)$ \\
\hline Medical students & $378(58.1)$ \\
\hline First-year & $66(10.1)$ \\
\hline Second-year & $68(10.4)$ \\
\hline Third-year & $71(10.9)$ \\
\hline Fourth-year & $63(9.7)$ \\
\hline Fifth-year & $63(9.7)$ \\
\hline Interns & $47(7.2)$ \\
\hline Clinical medical students & $244(37.63)$ \\
\hline Non-clinical medical students & $134(20.58)$ \\
\hline Residents & $273(41.9)$ \\
\hline First-year & $97(14.9)$ \\
\hline Second-year & $93(14.3)$ \\
\hline Third-year & $83(12.7)$ \\
\hline Clinical residents & $245(37.63)$ \\
\hline Non-clinical residents & $28(4.3)$ \\
\hline $18-24$ years & $314(48.2)$ \\
\hline $25-29$ years & $211(32.4)$ \\
\hline 30-34 years & $122(18.7)$ \\
\hline 35-39 years & $4(0.6)$ \\
\hline \multicolumn{2}{|l|}{ Religion } \\
\hline Hindu & $611(93.9)$ \\
\hline Buddhist & $7(1.1)$ \\
\hline Muslim & $28(4.3)$ \\
\hline Christian & $2(0.3)$ \\
\hline Sikh & $2(0.3)$ \\
\hline Yumanism & $1(0.2)$ \\
\hline \multicolumn{2}{|l|}{ Nationality } \\
\hline Nepalese & $566(86.9)$ \\
\hline Indian & $67(10.3)$ \\
\hline Sri Lankan & $6(0.9)$ \\
\hline Maldivian & $12(0.18)$ \\
\hline \multicolumn{2}{|l|}{ Relationship status } \\
\hline Married & $135(20.8)$ \\
\hline Non-married partner & $122(18.8)$ \\
\hline Single & $392(60.3)$ \\
\hline Divorced & $1(0.2)$ \\
\hline \multicolumn{2}{|l|}{ Socio-economic status } \\
\hline Upper & $215(33.1)$ \\
\hline Upper-middle & $302(46.5)$ \\
\hline Lower-middle & $121(18.6)$ \\
\hline Upper-lower & $11(1.7)$ \\
\hline Lower & $0(0)$ \\
\hline
\end{tabular}

Table 1 Socio-demographic profile of the participants, $N=651$ (Continued)

\begin{tabular}{ll}
\hline Socio-demographic features & $\mathbf{n ,}(\%)$ \\
\hline Current residence & \\
Home & $224(34.4)$ \\
Rented room & $240(36.9)$ \\
Hostel & $185(28.4)$ \\
Relative & $1(0.2)$ \\
Quarter & $1(0.2)$ \\
\hline
\end{tabular}

Among the six dimensions of stressors mentioned in Table 3, the ARS group of stressors caused high stress to participants (mean score-2.05) compared to other stressors. Almost all other stressor groups predominantly caused a moderate level of stress to most of the participants. The association of an individual group of stressors with outcome variables (Table 4) showed that depression, anxiety, and burnout were significantly less in the absence of these stressors.

\section{Independent correlates of depression-related symptoms}

Using univariate analysis, depression was found to be significantly correlated with many variables (Table 5). Further, we used logistic regression to assess the impact of available variables on the likelihood that the study participant would suffer from depressive symptoms. The final model (Table 6) was statistically significant $(P<0.001)$, indicating that the model was able to distinguish whether the study participant was suffering from depression or not. The final model explained between 18.4\% (Cox and Snell R squared) and 25.5\% (Nagelkerke $\mathrm{R}$ squared) of the variance in depression and correctly classified $84 \%$ of the cases. The logistic regression model shows that depression was significantly predicted by the presence of anxiety (OR 4.13; 95\% CI 2.64-6.57), personal burnout (OR 1.71; 95\% CI 1.03-2.83), and workrelated burnout (OR 1.78; 95\% CI 1.05-3.01). A student who was satisfied with his/her academic performance (OR $0.51 ; 95 \%$ CI $0.33-0.80$ ) was less likely to get depressed.

\section{Independent correlates of anxiety-related symptoms}

Many variables which were associated with anxietyrelated symptoms were shown by the univariate analysis (Table 5). Multivariable logistic regression analysis showed those variables which correlated independently and strongly with anxiety-related symptoms. The final model (Table 7) was statistically significant $(P=0.049)$, indicating that the model was able to distinguish whether the study participant was suffering from anxiety or not. The final model explained between 23.4\% (Cox and Snell R squared) and 31.3\% (Nagelkerke R squared) of the variance in anxiety and correctly classified $81 \%$ of 
Table 2 Clinical and behavioral characteristics of the participants

\begin{tabular}{|c|c|}
\hline Features & $\boldsymbol{n}(\%, 95 \mathrm{Cl})^{\mathrm{a}}$ \\
\hline Suicidal thoughts & $41(6.3,4.6-8.4)$ \\
\hline Thoughts of dropping out & $79(12.1,9.7-14.9)$ \\
\hline Previous history of mental disorders & $35(5.4,3.8-7.4)$ \\
\hline Currently receiving treatment for mental health disorders & $5(0.8,0.2-1.8)$ \\
\hline Family history of mental health problems & $55(8.4,6.4-10.9)$ \\
\hline Sleep hours, mean $(S D)$ & $7(1)$ \\
\hline Adequate, $n(\%)$ & $441(67.7,64-71.3)$ \\
\hline Inadequate & $210(32.3,28.7-36)$ \\
\hline Not satisfied with career choice & $145(22.31,19.1-25.7)$ \\
\hline Not satisfied with academic performance & $307(47.23,43.2-51.1)$ \\
\hline Involvement in extracurricular activities & $221(34,30.3-37.7)$ \\
\hline Alcohol & $393(60.4,56.5-64.1)$ \\
\hline Cigarette & $241(37.1,33.3-40.9)$ \\
\hline Marijuana & $100(15.4,12.7-18.4)$ \\
\hline Substance use & $398(61.14,57.3-64.9)$ \\
\hline Depression & $202(31,27.5-34.7)$ \\
\hline Anxiety & $295(45.3,41.4-49.2)$ \\
\hline Burnout & $318(48.8,44.9-52.7)$ \\
\hline Personal burnout & $266(40.8,37.1-44.7)$ \\
\hline Work-related burnout & $210(32.3,28.7-36)$ \\
\hline Patient-related burnout & $105(16.1,13.4-19.2)$ \\
\hline
\end{tabular}

Note. ${ }^{a} 95 \% \mathrm{Cl}, 95 \%$ Confidence Interval

the cases. Female gender (OR 1.83; 95\% CI 1.12-3.01), depression (OR 4.04; 95\% CI 2.51-6.62), personal burnout (OR 1.69; 95\% CI 1.04-2.76), TLRS (OR 1.74; 95\% CI 1.11-2.73), and past history of mental illness (OR 2.57; 95\% CI 1.09-6.48) were positively associated with anxiety. Whereas, being satisfied with academic performance $(O R$ 0.60; 95\% CI 0.38-0.93), getting adequate sleep (OR 0.52; 95\% CI 0.31-0.88), being a second-year resident (OR 0.29; 95\% CI 0.12-0.72), and being involved in extracurricular activities less frequently were negatively correlated with anxiety. This was more clearly seen by releveling the variable 'Extracurricular involvement' so that the reference class for dummy coding was 'never'. In doing so, anxiety was positively predicted in students who were 'always' involving in extracurricular activities $(\beta=0.27$, OR $1.31 ; 95 \%$ CI $0.21-6.61)$. But it was nonsignificant $(P=0.76)$.

\section{Independent correlates of burnout-related symptoms}

Many variables, that were associated with burnout symptoms, were shown by the univariate analysis (Table 5). Logistic regression was used to assess the impact of available variables on the likelihood that the study participant would suffer from burnout or not. The final model (Table 8) was statistically significant $(P<0.001)$, indicating that the model was able to distinguish whether the study participant was suffering from burnout or not. The final model explained between 26.2\% (Cox and Snell R squared) and 35\% (Nagelkerke R squared) of the variance in burnout and correctly classified $67 \%$ of the cases. Depression (OR 2.03; 95\% CI 1.26-3.29), anxiety (OR 2.37; 95\% CI 1.51$3.75)$, being a first-year resident (OR 2.38; 95\% CI 1.02-5.69), DRS (OR 2.06; 95\% CI 1.30-3.28), and a rare/never involvement in extracurricular activities were risk-enhancing correlates. Substance use was nearly the significant predictor of burnout $(P=0.06$, OR 1.57; 95\% CI 0.99-2.50).

\section{Discussions}

In the present study, the prevalence of depression, anxiety, and burnout among medical students and residents, and their possible association with predictor variables were assessed. Burnout was more prevalent than anxiety and depression in the study population: 48.8, 45.31, and $31.03 \%$ respectively. Residents suffered more burnout and depression (64.5 and 33.7\%) than medical students (37.6 and 29.1\%). However, medical students reported more 


\section{a Depression by years of medical school}

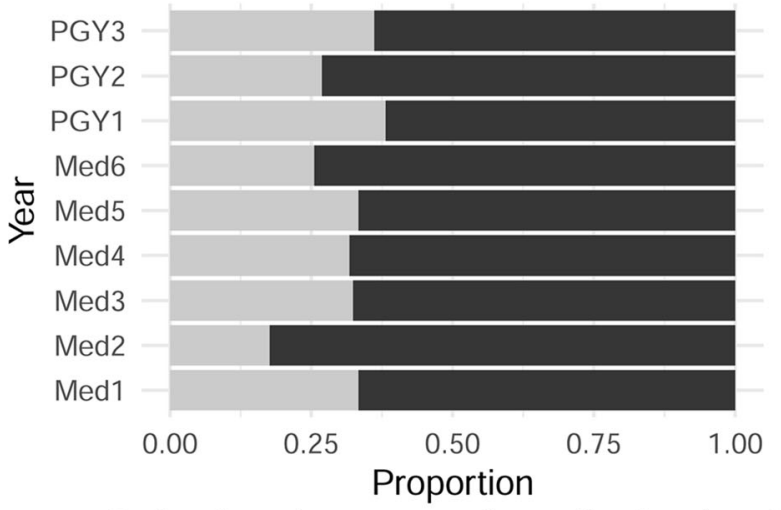

Depression

Present

Absent

b Anxiety by years of medical school

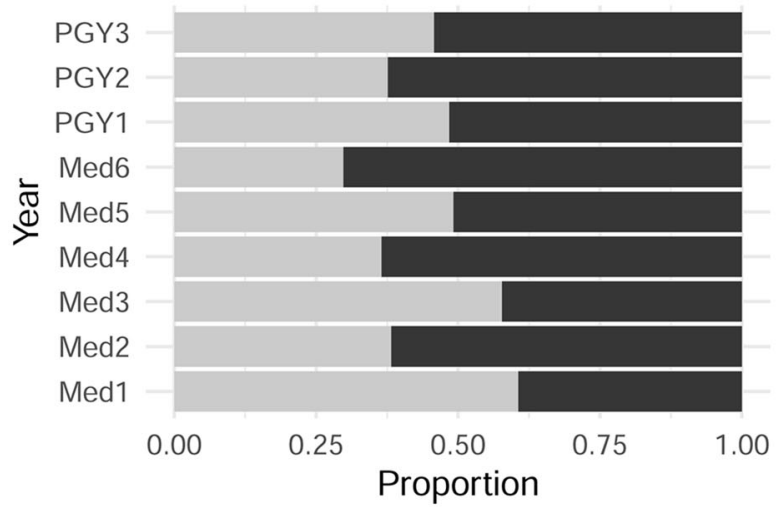

Anxiety

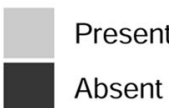

c Burnout by years of medical school

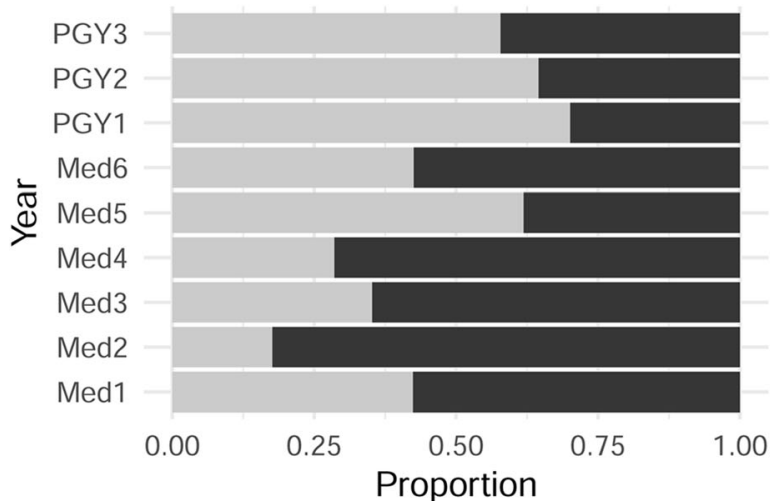

Burnout

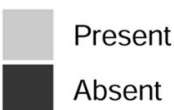

Fig. 1 Depression (a), anxiety (b) and burnout (c) according to the years of training of participants. (Med1-Med5: First-year to final year medical students, Med6: Interns, PGY1-3: First year to third-year residents)

anxiety symptoms compared to residents, $46.3 \%$ vs 44\%. These data closely resembled with findings from other studies. For example, the prevalence of depression in medical students as seen in our study was similar to the global prevalence of depression among medical students $(28 \%)$ as reported in a meta-analysis [36]. Similarly, a number of Nepalese studies [18-20] also reported similar prevalence of depression (29-30\%) among medical students. The prevalence of depressed residents seen in our study was closer to the pooled prevalence of $28.8 \%$ reported by Mata et al. [69] in 2015. As only the medical students were included in the previous studies, we currently have no available data concerning resident physicians for comparison. The proportion of burnout seen among medical students in the study was slightly lower than the estimated prevalence of $44.2 \%$ burnout in a recently published 
Table 3 Domain-wise distribution of stress among the study population

\begin{tabular}{|c|c|c|c|c|c|c|}
\hline Domains of stressors & Mild, $\boldsymbol{n}(\%)$ & Moderate, $\boldsymbol{n}(\%)$ & High, $\boldsymbol{n}(\%)$ & Severe, $\boldsymbol{n}(\%)$ & Mean score & Grade \\
\hline$\overline{\text { ARS }}$ & $93(14.3)$ & $264(40.6)$ & $213(32.7)$ & $81(12.4)$ & 2.05 & High \\
\hline IRS & $231(35.5)$ & $236(36.3)$ & $141(21.7)$ & $43(6.6)$ & 1.58 & Moderate \\
\hline TLRS & $261(40.1)$ & $280(43)$ & $83(12.8)$ & $27(4.1)$ & 1.47 & Moderate \\
\hline SRS & $262(40.2)$ & $275(42.2)$ & $97(14.9)$ & $17(2.6)$ & 1.45 & Moderate \\
\hline DRS & $367(56.4)$ & $201(30.9)$ & $62(9.5)$ & $21(3.2)$ & 1.2 & Moderate \\
\hline GARS & 225 (34.6) & $263(40.4)$ & $133(20.4)$ & $30(4.6)$ & 1.45 & Moderate \\
\hline
\end{tabular}

Note. ARS Academic Related Stressor, IRS Interpersonal and intrapersonal Related stressor, TLRS Teaching and Learning Related Stressor, SRS Social Related Stressor DRS Drive and Desire Related Stressor, GARS Group Activities Related Stressor

meta-analysis [70]. The prevalence of burnout among residents in our study was higher than the aggregate prevalence (51\%) reported by Low et al. [32] in their meta-analysis of the prevalence of burnout in medical and surgical residents. The proportion of anxious medicals students was slightly higher than what was reported in a previous Nepalese study (41.1\%), which included medical students from two medical colleges [19]. However, anxiety seen among medical students in our study was much greater than what was reported in an Ethiopian study (30.1\%) [71]. Consistent with previous studies [72, 73], academic-related stressors were causing high stress to the participants.

\section{Predictors of depression}

The logistic regression model showed that depression, anxiety, and burnout were independently and strongly correlated with each other. Presence of one significantly predicted the occurrence of the other two. Studies done in different settings have found a significant association of burnout with depression [38, 46] and anxiety [46], consistent with our finding. In the same study [46], anxiety was identified as a significant predictor of depression.

Those who were satisfied with their academic performance were less likely to be depressed and anxious. This association between academic performace and depression has been reported in a similar Indian

Table 4 Association of stressors with depression, anxiety, and burnout

\begin{tabular}{|c|c|c|c|}
\hline Stressor groups & $\begin{array}{l}\text { Depression, } \\
X^{2}, \boldsymbol{P} \text {-value } \\
\boldsymbol{n}(\%)\end{array}$ & $\begin{array}{l}\text { Anxiety, } \\
\mathbf{X}^{2}, \boldsymbol{P} \text {-value } \\
\boldsymbol{n}(\%)\end{array}$ & $\begin{array}{l}\text { Burnout, } \\
X^{2}, P \text {-value } \\
\boldsymbol{n}(\%)\end{array}$ \\
\hline$\overline{\mathrm{ARS}}$ & $9.69,0.002$ & $13.19, P<0.001$ & $15.25, P<0.0001$ \\
\hline Present $(n=558)$ & $186(33.3)$ & $269(48.2)$ & $290(52)$ \\
\hline Absent $(n=93)$ & $16(17.2)$ & $26(28)$ & $28(30.1)$ \\
\hline IRS & $8.72,0.003$ & $15.18, P<0.0001$ & $15.26, P<0.0001$ \\
\hline Present $(n=420)$ & $147(35)$ & $214(51)$ & $229(54.5)$ \\
\hline Absent $(n=231)$ & $55(23.8)$ & $81(35.1)$ & $89(38.5)$ \\
\hline TLRS & $26.87, P<0.0001$ & $32.11, P<0.0001$ & $55.32, P<0.0001$ \\
\hline Present $(n=390)$ & $151(38.7)$ & $212(54.4)$ & $237(60.8)$ \\
\hline Absent $(n=261)$ & $51(19.5)$ & $83(31.8)$ & $81(31)$ \\
\hline SRS & $7.93,0.005$ & $9.04,0.003$ & $8.27,0.004$ \\
\hline Present $(n=389)$ & $137(35.2)$ & $195(50.1)$ & $208(53.5)$ \\
\hline Absent $(n=262)$ & $65(24.8)$ & $100(38.2)$ & $110(42)$ \\
\hline DRS & $19.54, P<0.0001$ & $7.55,0.006$ & $63.17, P<0.0001$ \\
\hline Present $(n=284)$ & $114(40.1)$ & $146(51.4)$ & $189(66.5)$ \\
\hline Absent $(n=367)$ & $88(24)$ & 149 (40.6) & $129(35.1)$ \\
\hline GARS & $32.12, P<0.0001$ & $29.78, P<0.0001$ & $37.03, P<0.0001$ \\
\hline Present $(n=426)$ & $164(38.5)$ & $226(53.1)$ & $245(57.5)$ \\
\hline Absent $(n=225)$ & $38(16.9)$ & $69(30.7)$ & $73(32.4)$ \\
\hline
\end{tabular}

Note. ARS Academic Related Stressor, IRS Interpersonal and intrapersonal Related stressor, TLRS Teaching and Learning Related Stressor, SRS Social Related Stressor, DRS Drive and Desire Related Stressor; GARS Group Activities Related Stressor all $P$-values were obtained by using the Chi-squared test. 
Table 5 Univariate analysis for depression, anxiety, and burnout, and selected demographic variables

\begin{tabular}{|c|c|c|c|}
\hline Participant's characteristics & $\begin{array}{l}\text { Depression } \\
X^{2}, \boldsymbol{P} \text {-value } \\
\boldsymbol{n}(\%)\end{array}$ & $\begin{array}{l}\text { Anxiety } \\
x^{2}, \boldsymbol{P} \text {-value } \\
\boldsymbol{n}(\%)\end{array}$ & $\begin{array}{l}\text { Burnout } \\
X^{2}, P \text {-value } \\
n(\%)\end{array}$ \\
\hline Gender & $7.28,0.007$ & $16.93, P<0.0001$ & $3.93,0.05$ \\
\hline Male $(n=495)$ & $140(28.3)$ & $202(40.8)$ & $231(46.7)$ \\
\hline Female $(n=156)$ & $62(39.7)$ & $93(59.6)$ & $87(55.8)$ \\
\hline Trainee type & $1.57,0.21$ & $0.35,0.55$ & $45.92, P<0.0001$ \\
\hline Medical Students $(n=378)$ & $110(29.1)$ & $175(46.3)$ & $142(37.6)$ \\
\hline Residents $(n=273)$ & $92(33.7)$ & $120(44)$ & $176(64.5)$ \\
\hline Years in training & $10.81,0.21$ & $21.57,0.006$ & $77.63, P<0.0001$ \\
\hline \multicolumn{4}{|l|}{ Medical student } \\
\hline First-year $(n=66)$ & $22(33.3)$ & $40(60.6)$ & $28(42.4)$ \\
\hline Second-year $(n=68)$ & $12(17.7)$ & $26(38.2)$ & $12(17.6)$ \\
\hline Third-year $(n=71)$ & $23(32.4)$ & $41(57.8)$ & $25(35.2)$ \\
\hline Fourth-year $(n=63)$ & $20(31.8)$ & $23(36.5)$ & $18(28.6)$ \\
\hline Fifth-year $(n=63)$ & $21(33.3)$ & $31(49.2)$ & $39(61.9)$ \\
\hline Interns $(n=47)$ & $12(25.5)$ & $14(29.8)$ & $20(42.6)$ \\
\hline \multicolumn{4}{|l|}{ Residents } \\
\hline First-year $(n=97)$ & $37(38.1)$ & $47(48.5)$ & $68(70.1)$ \\
\hline Second-year $(n=93)$ & $25(26.9)$ & $35(37.6)$ & $60(64.5)$ \\
\hline Third-year $(n=83)$ & $30(36.1)$ & $38(45.8)$ & $48(57.8)$ \\
\hline Clinical or non-clinical med student or resident & $6.57,0.09$ & $1.10,0.78$ & $58.78, P<0.0001$ \\
\hline Clinical med std $(n=244)$ & $76(31.2)$ & $109(44.7)$ & $102(41.8)$ \\
\hline Non-clinical med std $(n=134)$ & $34(25.4)$ & $66(49.3)$ & $40(29.9)$ \\
\hline Clinical res $(n=245)$ & $87(35.5)$ & $108(44.1)$ & $165(67.3)$ \\
\hline Non-clinical res $(n=28)$ & $5(17.9)$ & $12(42.9)$ & $11(39.3)$ \\
\hline Age category & $0.13^{\mathrm{a}}$ & $0.75^{\mathrm{a}}$ & $P<0.0001^{a}$ \\
\hline $18-24$ years $(n=314)$ & $88(28)$ & $148(47.1)$ & $109(34.7)$ \\
\hline $25-29$ years $(n=211)$ & $65(30.8)$ & $92(43.6)$ & $130(61.6)$ \\
\hline $30-34$ years $(n=122)$ & $48(39.3)$ & $54(44.3)$ & $76(62.3)$ \\
\hline $35-39$ years $(n=4)$ & $1(25)$ & $1(25)$ & $3(75)$ \\
\hline Satisfied with academic performance & $43.2, P<0.0001$ & $50.1, P<0.0001$ & $12, P<0.001$ \\
\hline Satisfied $(n=344)$ & $68(19.8)$ & $111(32.3)$ & $146(42.4)$ \\
\hline Dissatisfied $(n=307)$ & $134(43.6)$ & $184(59.9)$ & $172(56)$ \\
\hline Satisfied with career choice & $28, P<0.0001$ & $22.9, P<0.0001$ & $28.2, P<0.0001$ \\
\hline Satisfied $(n=506)$ & $131(25.9)$ & $204(40.3)$ & $219(43.3)$ \\
\hline Dissatisfied $(n=145)$ & $71(49)$ & $91(62.8)$ & $99(68.3)$ \\
\hline Extracurricular involvement & $P<0.001^{a}$ & $0.12^{\mathrm{a}}$ & $36.9, P<0.0001$ \\
\hline Always $(n=56)$ & 16 (28.6) & $31(55.4)$ & $15(26.8)$ \\
\hline Often $(n=166)$ & $36(21.7)$ & $65(39.2)$ & $70(42.2)$ \\
\hline Sometimes $(n=240)$ & $70(29.2)$ & $112(46.7)$ & $111(46.3)$ \\
\hline Rarely $(n=177)$ & $75(42.4)$ & $79(44.6)$ & $111(62.7)$ \\
\hline Never $(n=12)$ & $5(41.7)$ & $8(66.7)$ & $11(91.7)$ \\
\hline Adequacy of sleep & $2.9,0.09$ & $1.7,0.19$ & $22.7, P<0.0001$ \\
\hline Adequate $(n=441)$ & $127(28.8)$ & $192(43.5)$ & $187(42.4)$ \\
\hline Inadequate $(n=210)$ & $75(35.7)$ & $103(49)$ & $131(62.4)$ \\
\hline
\end{tabular}


Table 5 Univariate analysis for depression, anxiety, and burnout, and selected demographic variables (Continued)

\begin{tabular}{|c|c|c|c|}
\hline Participant's characteristics & $\begin{array}{l}\text { Depression } \\
X^{2}, \boldsymbol{P} \text {-value } \\
\boldsymbol{n}(\%)\end{array}$ & $\begin{array}{l}\text { Anxiety } \\
X^{2}, \boldsymbol{P} \text {-value } \\
\boldsymbol{n}(\%)\end{array}$ & $\begin{array}{l}\text { Burnout } \\
X^{2}, P \text {-value } \\
\boldsymbol{n}(\%)\end{array}$ \\
\hline Substance use & $0.37,0.54$ & $1.41,0.23$ & $6.29,0.01$ \\
\hline Using $(n=398)$ & $127(31.9)$ & $173(43.5)$ & $210(52.8)$ \\
\hline Not using $(n=253)$ & 75 (29.6) & $122(48.2)$ & $108(42.7)$ \\
\hline
\end{tabular}

Note. med std medical student, res resident; ${ }^{a}: P$-values calculated from Fisher's exact test; all other $P$-values were obtained by using the Chi-squared test.

study in which 237 medical students were surveyed [74]. Knowing this, one might be curious about the effects of academic related matters on students' mental health. We found that academic-related stressors (ARS) caused high-grade stress among study participants. ARS refers to educational or student events like examination systems, assessment methods, grading methods, acadmic schedule, getting poor marks in examination, high self expectation to do well in studies, large amount of content to be studied, having difficulty to understand content, lack of time to do revision, and having difficulty answering questions given by teachers [75]. In a 2018 study in western Nepal, more than $50 \%$ of second-year medical students were found to have suffered from academic stress [17]. Students who were dissatisfied with their academia would be less likely content with themselves, thus contributing to their stress, anxiety, and depression.

\section{Predictors of anxiety}

Being a female was highly predictive of anxiety symptoms. Similar results were presented by Kebede et al. [71] in their study among medical students of Ethiopia. It might be because, males are less likely to disclose psychological suffering and seek help, compared to females [76]. However, gender was not a significant correlate for depression and burnout in our logistic model. The finding was in agreement with the finding of a meta-analysis of burnout among medical students [70]. In contrast, there were debating issues considering the effect of gender on depression among medical students. Many studies have found a significantly higher prevalence of depression in females [77-79], while a study in 1988 argued that female medical students were not more susceptible to depressive symptomatology than males [80].

Students who felt stressed with TLRS were more likely to feel depressed and anxious, which was in line with a previous review in which stress led to depression and

Table 6 Final model of a multivariable logistic regression analysis predicting depression among medical students and residents

\begin{tabular}{|c|c|c|c|c|}
\hline Predictor & $\beta$ & $S E$ & $P$ & OR $(95 \% \mathrm{Cl})$ \\
\hline Intercept & -1.690 & 0.240 & $<0.001$ & $0.18(0.114-0.291)$ \\
\hline Anxiety & - & - & - & - \\
\hline Absent $^{a}$ & - & - & - & - \\
\hline Present & 1.412 & 0.232 & $<0.001$ & $4.129(2.639-6.574)$ \\
\hline Personal burnout & - & - & - & - \\
\hline Absent $^{a}$ & - & - & - & - \\
\hline Present & 0.534 & 0.258 & 0.04 & $1.706(1.026-2.831)$ \\
\hline Work-related burnout & - & - & - & - \\
\hline Absent $^{a}$ & - & - & - & - \\
\hline Present & 0.576 & 0.267 & 0.03 & $1.780(1.054-3.009)$ \\
\hline Satisfied with academic performance & - & - & - & - \\
\hline Dissatisfied $^{\text {a }}$ & - & - & - & - \\
\hline Satisfied & -0.666 & 0.224 & 0.003 & $0.514(0.330-0.796)$ \\
\hline Test & $x^{2}$ & $d f$ & P & \\
\hline Hosmer and Lemeshow test & 4.09 & 8 & 0.85 & \\
\hline Likelihood ratio test & 4 & 97.68 & $<0.001$ & \\
\hline
\end{tabular}

Note. ${ }^{a}$ referent for dummy coding. The coefficient $(\beta)$ in the model indicates the direction (positive or negative) and the significance of the relationship to the outcome variable (depression). Null deviance: 612.43 on 479 degrees of freedom (df), Residual deviance: 514.75 on $475 d f$, AIC (Akaike Information Criterion): 524.75, AUC (Area Under Receiver Operating Characteristic Curve): 0.71 
Table 7 Final model of a multivariable logistic regression analysis predicting anxiety among medical students and residents

\begin{tabular}{|c|c|c|c|c|}
\hline Predictor & $\beta$ & $S E$ & $P$ & OR $(95 \% \mathrm{Cl})$ \\
\hline Intercept & 1.051 & 0.534 & 0.049 & $2.860(1.019-8.309)$ \\
\hline Gender & - & - & - & - \\
\hline Male ${ }^{a}$ & - & - & - & - \\
\hline Female & 0.604 & 0.251 & 0.016 & $1.830(1.122-3.010)$ \\
\hline Year of study & - & - & - & - \\
\hline Med1 ${ }^{\text {a }}$ & - & - & - & - \\
\hline Med2 & -0.605 & 0.458 & 0.186 & $0.546(0.220-1.331)$ \\
\hline Med3 & -0.075 & 0.411 & 0.855 & $0.928(0.413-2.077)$ \\
\hline Med4 & -0.901 & 0.486 & 0.064 & $0.406(0.154-1.043)$ \\
\hline Med5 & -0.628 & 0.463 & 0.175 & $0.534(0.214-1.319)$ \\
\hline Med6 & -0.810 & 0.533 & 0.129 & $0.445(0.153-1.248)$ \\
\hline PGY1 & -0.873 & 0.452 & 0.053 & $0.418(0.170-1.005)$ \\
\hline PGY2 & -1.229 & 0.462 & 0.008 & $0.293(0.116-0.716)$ \\
\hline PGY3 & -0.787 & 0.451 & 0.081 & $0.455(0.186-1.096)$ \\
\hline Depression & - & - & - & - \\
\hline Absent $^{a}$ & - & - & - & - \\
\hline Present & 1.396 & 0.247 & $<0.001$ & $4.039(2.509-6.620)$ \\
\hline Personal burnout & - & - & - & - \\
\hline Absent ${ }^{a}$ & - & - & - & - \\
\hline Present & 0.526 & 0.247 & 0.033 & $1.693(1.043-2.755)$ \\
\hline Patient-related burnout & - & - & - & - \\
\hline Absent ${ }^{a}$ & - & - & - & - \\
\hline Present & 0.594 & 0.312 & 0.056 & $1.810(0.990-3.370)$ \\
\hline Satisfied with academic performance & - & - & - & - \\
\hline Dissatisfied $^{a}$ & - & - & - & - \\
\hline Satisfied & -0.516 & 0.225 & 0.022 & $0.597(0.383-0.928)$ \\
\hline TLRS & - & - & - & - \\
\hline Absent ${ }^{a}$ & - & - & - & - \\
\hline Present & 0.555 & 0.229 & 0.015 & $1.743(1.114-2.733)$ \\
\hline Past history of mental illness & - & - & - & - \\
\hline Absent $^{a}$ & - & - & - & - \\
\hline Present & 0.943 & 0.450 & 0.036 & $2.568(1.092-6.480)$ \\
\hline Extracurricular involvement & - & - & - & - \\
\hline Always ${ }^{a}$ & - & - & - & - \\
\hline Often & -1.003 & 0.401 & 0.012 & $0.367(0.165-0.799)$ \\
\hline Sometimes & -0.761 & 0.340 & 0.051 & $0.467(0.215-0.995)$ \\
\hline Rarely & -1.317 & 0.446 & 0.003 & $0.268(0.110-0.634)$ \\
\hline Never & -0.268 & 0.862 & 0.756 & $0.765(0.151-4.745)$ \\
\hline Sleep adequacy & - & - & - & - \\
\hline Inadequate sleep ${ }^{a}$ & - & - & - & - \\
\hline Adequate sleep & -0.650 & 0.269 & 0.016 & $0.522(0.306-0.882)$ \\
\hline Test & $x^{2}$ & $d f$ & P & \\
\hline Hosmer and Lemeshow test & 8.49 & 8 & 0.387 & \\
\hline Likelihood ratio test & 128.22 & 20 & $<0.001$ & \\
\hline
\end{tabular}

Note. ${ }^{a}$ referent for dummy coding. TLRS, Teaching and Learning Related Stressor. Null deviance: 663.55 on $479 d f$, Residual deviance: 535.33 on $459 d f$, AIC: 577.33, AUC: 0.81 
Table 8 Final model of a multivariable logistic regression analysis predicting burnout among medical students and residents

\begin{tabular}{|c|c|c|c|c|}
\hline Predictor & $\beta$ & $S E$ & $P$ & OR $(95 \% \mathrm{Cl})$ \\
\hline Intercept & -2.595 & 0.684 & $<0.001$ & $0.075(0.019-0.277)$ \\
\hline Year of study & - & - & - & - \\
\hline Med1 ${ }^{\text {a }}$ & - & - & - & - \\
\hline Med2 & -0.605 & 0.473 & 0.201 & $0.546(0.211-1.362)$ \\
\hline Med3 & -0.370 & 0.402 & 0.357 & $0.691(0.312-1.515)$ \\
\hline Med4 & -0.626 & 0.482 & 0.194 & $0.535(0.204-1.359)$ \\
\hline Med5 & 0.138 & 0.450 & 0.758 & $1.149(0.475-2.782)$ \\
\hline Med6 & 0.173 & 0.523 & 0.741 & $1.189(0.423-3.312)$ \\
\hline PGY1 & 0.868 & 0.437 & 0.047 & $2.382(1.021-5.690)$ \\
\hline PGY2 & 0.587 & 0.455 & 0.197 & $1.799(0.741-4.438)$ \\
\hline PGY3 & -0.027 & 0.439 & 0.952 & $0.974(0.411-2.309)$ \\
\hline Depression & - & - & - & - \\
\hline Absent $^{a}$ & - & - & - & - \\
\hline Present & 0.709 & 0.243 & 0.004 & $2.031(1.263-3.285)$ \\
\hline Anxiety & - & - & - & - \\
\hline Absent ${ }^{a}$ & - & - & - & - \\
\hline Present & 0.864 & 0.232 & $<0.001$ & $2.374(1.510-3.753)$ \\
\hline Satisfied with career choice & - & - & - & - \\
\hline Dissatisfied $^{a}$ & - & - & - & - \\
\hline Satisfied & -0.499 & 0.262 & 0.057 & $0.607(0.362-1.014)$ \\
\hline Extracurricular involvement & - & - & - & - \\
\hline Always $^{a}$ & - & - & - & - \\
\hline Often & 0.591 & 0.413 & 0.152 & $1.806(0.817-4.145)$ \\
\hline Sometimes & 0.449 & 0.401 & 0.263 & $1.567(0.724-3.519)$ \\
\hline Rarely & 0.996 & 0.446 & 0.025 & $2.709(1.145-6.618)$ \\
\hline Never & 2.324 & 1.165 & 0.046 & $10.215(1.446-6.618)$ \\
\hline ARS & - & - & - & - \\
\hline Absent $^{a}$ & - & - & - & - \\
\hline Present & 0.760 & 0.394 & 0.054 & $2.137(1.009-4.768)$ \\
\hline IRS & - & - & - & - \\
\hline Absent $^{a}$ & - & - & - & - \\
\hline Present & 0.412 & 0.245 & 0.092 & $1.511(0.936-2.446)$ \\
\hline DRS & - & - & - & - \\
\hline Absent $^{a}$ & - & - & - & - \\
\hline Present & 0.723 & 0.236 & 0.002 & $2.061(1.299-3.282)$ \\
\hline Substance use & - & - & - & - \\
\hline Not using ${ }^{a}$ & - & - & - & - \\
\hline Using & 0.450 & 0.236 & 0.057 & $1.568(0.989-2.502)$ \\
\hline Test & $x^{2}$ & $d f$ & P & \\
\hline Hosmer and Lemeshow test & 12.7 & 8 & 0.12 & \\
\hline Likelihood ratio test & 145.9 & 19 & $<0.001$ & \\
\hline
\end{tabular}

Note. ${ }^{2}$ Referent for dummy coding. ARS, Academic Related Stressor; IRS, Interpersonal and intrapersonal Related stressor; DRS, Drive and Desire Related Stressor. Null deviance: 664.41 on 479 df, Residual deviance: 518.51 on 460 df, AIC: 558.51, AUC: 0.84 
anxiety [81]. TLRS relates to the teachers' competency to teach and supervise students, the clarity of learning objectives delivered to students, and appropriateness of tasks given to students [75]. This might be conveying a message that the present way of teaching and learning activity is not being as friendly to students as it should be. A thorough change in the present curriculum might be necessary. Exceptional results have been seen by making changes in the results of examinations to pass/fail grading system [82].

Sleep duration is one of the important factors which determines sleep quality [83]. In our study, anxiety was unlikely in those getting adequate sleep. This matches well with several studies on sleep quality and psychological morbidity among university students. For instance, Lemma et al. [84] found a strong correlation of the symptoms of depression and anxiety with sleep quality. Poor sleep quality was also found to be associated with poor academic performance among medical students [85].

Second-year residents were less likely to suffer from anxiety symptoms than first-year medical students. The difficulty accommodating to the new learning environment might have contributed to anxiety in first-year medical students. Being more mature, residents, on the other hand, are expected to be less apprehensive than the younger medical students. Probably, second-year residents might be feeling relieved from their hectic firstyear schedule. Many of the second-year resident physicians share their first year experience in which they frequently mention about their feeling of being overwhelmed by the tasks which were normally expected of them. During the second year, they might have an additional opportunity to delegate some of their tasks to the junior residents, probably reducing their perceived stress.

Someone who was frequently involving in extracurricular activities was more likely to develop anxiety. However, other studies are in disagreement with our results. Moor et al. [86] have found that exercise was associated with lower levels of anxiety, depression, and neurosis. Similarly, a reduction in anxiety sensitivity by both highand low-intensity exercises was noticed by BromanFulks et al. [87]. However, we have not specified the type of extracurricular activities. Similarly, we have not sought out the motivation behind participation in extracurricular activities as they have different effects in the experience of burnout $[88,89]$.

\section{Predictors of burnout}

Those who were less frequently involved in extracurricular activities were more likely to feel burnt out than others, though the association was not fairly significant. We feel the necessity to summarize some findings from other studies in this regard. Youssef [21] found that students who exercised regularly and had time to relax had lower rates of burnout. In contrast, a survey conducted among medical students in Saudi Arabia [90] found no significant association between burnout levels and the frequency of involvement in extracurricular activities. Similarly, to disagreement of our finding, Muzafar et al. [91] in their cross-sectional study of burnout among Pakistani medical students, have found that students who were less frequently involved in extracurricular activities had lower levels of burnout. It is possible that those students who were experiencing burnout might have used extracurricular involvement as a coping mechanism to lighten their feeling of burnout.

The first-year residents had significantly higher odds of being burnt out than others. The finding is consistent with a study in which a higher proportion of burnout was seen in first [38, 92] and second-year residents [92]. Another study reported that the second-year residents were less emotionally exhausted and had less psychosomatic symptoms compared to the time when they were in their first year [93]. The higher average age of enrollment of residents exposes them to different contextual and social factors, and pressures, which may influence their experience of burnout [94]. Besides, first year residents face higher work load in a new environment compared to their seniors. However, contrary to these findings, Michel et al. [95] have found a higher level of depersonalization among residents in their second and third years than they experienced in their first. What we feel is more important in our study is that residents were found more burnt out than medical students. Siu et al. [96] in their study among public doctors reached a similar conclusion. They have concluded that young and moderately experienced doctors who needed to work in shifts were more vulnerable to burnout. The median years of practice of doctors experiencing highburnout were 8.5 (range 5-15) years. In our context, the residents tend to belong to this young and moderately experienced group of doctors. Other factors like increased paperwork, clinical audits, lack of autonomy, and overwhelming duty hours might have contributed to residents' burnout in our setting. Besides, there is no advocacy to safeguard working conditions in our setting as in Europe [97] and the United States [98]. However, some studies contradicted our belief regarding duty hours in which no significant association was seen between the residents' burnout with duty hours [99, 100]. Interestingly, in the same study [100], burnout was found to be strongly correlated with quantitative work overload. In a recent study in Japanese residents, 
long work hours were significantly associated with the development of depressive symptoms [101]. Nonetheless, a meta-analysis has proposed reduction in duty-hours as a measure to decrease burnout in residents [102].

The presence of a higher degree of DRS significantly predicted burnout. DRS arises from an unwillingness to study medicine due to various reasons such as the field of medicine not being one's first priority, following friends to study medicine, parental wish to study medicine, wrongly choosing the specialty, and being demotivated after learning the reality of medicine [75]. The authors, unfortunately, came across a few circumstances in which some medical students became demotivated after living the reality of medicine. Most of them followed their parents' wish or dreamt of their higher social status before enrolling into the medical school. Later, they got dissatisfied with their chosen career. In this study, we have also found that those who were satisfied with their career choice were less likely to develop burnout $(P=0.057)$.

In a study conducted in the Netherlands among preclinical medical students, less than six hours of sleep per night was well correlated with burnout [103]. Though sleep adequacy was significantly associated with the burnout symptoms in univariate analysis, it failed to contribute to the best-fitted model. Similarly, married students felt significantly higher burnout than others during univariate analysis but failed to show its significance in the overall model. Though some studies reported significantly higher burnout among unmarried residents [92], we think the situation in our setting is different. Looking at our context, the families of married participants are expecting financial support from them. They may find it difficult to fulfill the emotional demands of their families in addition to their academic obligation causative to their experience of burnout.

Some limitations of the study are acknowledged. Being a cross-sectional study, causal relationships between the associations could not be established. So, multicenter studies with longitudinal follow-up design are still required to elucidate the course of depression, anxiety, and burnout. The levels of the outcome variables might be high due to ongoing exams of medical students. The statistical power may have been reduced as some variables were dichotomized. The variables that might be related to depression such as personality characteristics [104], social support systems, and the ongoing conflict between career life and personal life were not analyzed. We have not sought the frequency of consumption of abusive substances. The choice of response and the degree of honesty in disclosing one's problems might have been affected by the level of stigma in our setting. Similarly, we have not included information about specialty among residents. As the study was conducted in a single medical school, this may not be representative of the national outcomes of depression, anxiety, and burnout in medical students and residents. Since we have used screening tools in this study, confirmation of the findings of this study requires further clinical psychiatric diagnostic interview through the use of a structured psychiatric diagnostic instrument.

\section{Conclusions}

High prevalence of depression, anxiety, and burnout were seen among medical students and residents, with the predominant effect of high-grade academic-related stressors. The study will provide baseline data for future multicenter prospective studies. The researcher hopes that this will help the relevant authorities to effectively design strategies for mental well-being of future physicians. The strong correlation of TLRS with anxiety may be calling for more student-friendly curriculum. This can be achieved after a significant change in the present curriculum without undermining the objectives of medical learning.

\section{Supplementary information}

Supplementary information accompanies this paper at https://doi.org/10. 1186/s12888-020-02645-6.

\section{Additional file 1}

\section{Abbreviations}

ARS: Academic Related Stressor; AIC: Akaike Information Criterion; AUC: Area Under Receiver Operating Characteristic Curve; CBI: Copenhagen Burnout Inventory; DRS: Drive and Desire Related Stressor; GARS: Group Activities Related Stressor; HADS-A: Hospital Anxiety and Depression Scale-Anxiety; HADS-D: Hospital Anxiety and Depression Scale-Depression; IRS: Interpersonal and Intrapersonal Related Stressor; MSSQ: Medical Students' Stressor Questionnaire; SRS: Social Related Stressor; TLRS: Teaching and Learning Related Stressor; VIF: Variance Inflation Factor

\section{Acknowledgments}

The authors would like to express their thanks to Prof Dr. Amita Pradhan, People's Dental College and Hospital, Kathmandu, Nepal for her guidance during statistical analyses and Dr. Parikshit Chapagain, Tribhuvan University Institute of Medicine, Kathmandu, Nepal for proofreading the article.

\section{Authors' contributions}

NP and RK conducted the literature search, drafted the prevalence and discussion sections. NP drafted sections on epidemiological analysis. PT supervised the study. All authors made a critical revision of the manuscript for important intellectual content and contributed to the final manuscript. The authors read and approved the final manuscript.

\section{Funding}

The research received no specific grant from any funding agency, commercial or not-for-profit sectors. None of the authors' affiliation institutions had any influence on the design, implementation, analysis or interpretation of the data in the study.

Availability of data and materials

The datasets used and analyzed during the current study, and the scripts used during multivariable logistic regression analysis in R-software environment are available from the corresponding author upon reasonable request. 


\section{Ethics approval and consent to participate}

The research was performed in accordance with the Declaration of Helsinki and was approved by the Institutional Review Committee of the Institute of Medicine (Reference number- 305/075/076). The consent was implied through the completion of the questionnaire. The name, address or signature of the participant were not included in the questionnaire to keep the identity of the participant anonymous.

\section{Consent for publication}

Not applicable.

\section{Competing interests}

The authors declare that they have no conflicts of interest.

\section{Author details}

${ }^{1}$ Tribhuvan University Institute of Medicine, Kathmandu, Nepal. ${ }^{2}$ Department of Psychiatry and Mental Health, Tribhuvan University Institute of Medicine, Kathmandu, Nepal.

Received: 21 September 2019 Accepted: 1 May 2020

Published online: 15 June 2020

\section{References}

1. Carson AJ, Dias S, Johnston A, McLoughlin M, O'connor M, Robinson B, et al. Mental health in medical students a case control study using the 60 item general health questionnaire. Scott Med J. 2000;45(4):115-6. https:// doi.org/10.1177/003693300004500406.

2. Rosal MC, Ockene IS, Ockene JK, Barrett SV, Ma Y, Hebert JR. A longitudinal study of students' depression at one medical school. Acad Med. 1997;72(6): 542-6. https://doi.org/10.1097/00001888-199706000-00022.

3. Smith CK, Peterson DF, Degenhardt BF, Johnson JC. Depression, anxiety, and perceived hassles among entering medical students. Psychol Health Med. 2007;12(1):31-9. https://doi.org/10.1080/13548500500429387.

4. Brazeau CM, Shanafelt T, Durning SJ, Massie FS, Eacker A, Moutier C, et al. Distress among matriculating medical students relative to the general population. Acad Med. 2014;89(11):1520-5. https://doi.org/10.1097/ACM. 0000000000000482

5. Sreeramareddy CT, Shankar PR, Binu V, Mukhopadhyay C, Ray B, Menezes RG. Psychological morbidity, sources of stress and coping strategies among undergraduate medical students of Nepal. BMC Med Educ. 2007;7(1):26. https://doi.org/10.1186/1472-6920-7-26.

6. Guthrie EA, Black D, Shaw CM, Hamilton J, Creed FH, Tomenson B. Embarking upon a medical career: psychological morbidity in first year medical students. Med Educ. 1995;29(5):337-41. https://doi.org/10.1111/j. 1365-2923.1995.tb00022.x.

7. Wolf TM, Faucett JM, Randall HM, Balson PM. Graduating medical students' ratings of stresses, pleasures, and coping strategies. J Med Educ. 1988. https://doi.org/10.1097/00001888-198808000-00008.

8. Dahlin ME, Runeson B. Burnout and psychiatric morbidity among medical students entering clinical training: a three year prospective questionnaire and interview-based study. BMC Med Educ. 2007;7(1):6. https://doi.org/10. 1186/1472-6920-7-6

9. Stewart SM, Lam T, Betson C, Wong C, Wong AM. A prospective analysis of stress and academic performance in the first two years of medical school. Med Educ. 1999. https://doi.org/10.1046/j.1365-2923.1999.00294.X.

10. Chew-Graham CA, Rogers A, Yassin N. I wouldn't want it on my CV or their records': medical students' experiences of help-seeking for mental health problems. Med Educ. 2003;37(10):873-80. https://doi.org/10.1046/j.13652923.2003.01627.x

11. Wear D. "Face-to-face with it": medical students' narratives about their endof-life education. Acad Med. 2002;77(4):271-7. https://doi.org/10.1097/ 00001888-200204000-00003.

12. Sheehan KH, Sheehan DV, White K, Leibowitz A, Baldwin DC. A pilot study of medical student 'abuse': student perceptions of mistreatment and misconduct in medical school. JAMA. 1990;263(4):533-7. https://doi.org/10. 1001/jama.1990.03440040072031.

13. Dyrbye LN, West CP, Satele D, Boone S, Tan L, Sloan J, et al. Burnout among US medical students, residents, and early career physicians relative to the general US population. Acad Med. 2014:89(3):443-51. https://doi.org/10. 1097/ACM.0000000000000134.
14. Guthrie E, Black D, Bagalkote H, Shaw C, Campbell M, Creed F. Psychological stress and burnout in medical students: a five-year prospective longitudinal study. J R Soc Med. 1998;91(5):237-43. https://doi.org/10.1177/ 014107689809100502

15. Dyrbye LN, Thomas MR, Shanafelt TD. Medical student distress: causes, consequences, and proposed solutions. MayoClinProc. 2005;80(12):1613-22. https://doi.org/10.4065/80.12.1613.

16. Lins L, Carvalho FM, Menezes MS, Porto-Silva L, Damasceno H. Healthrelated quality of life of students from a private medical school in Brazil. Int J Med Educ. 2015;6:149-54. https://doi.org/10.5116/ijme.563a.5dec doi:10. 5116/ijme.563a.5dec

17. Dhami D, Singh A, Shah G. Prevalence of depression and use of antidepressant in basic medical sciences students of Nepalgunj medical college, Cherapani, Nepal. J Nepalgunj Medical College. 2018;16(1):32-6. https://doi.org/10.3126/jngmc.v16i1.24224.

18. Adhikari A, Dutta A, Sapkota S, Chapagain A, Aryal A, Pradhan A. Prevalence of poor mental health among medical students in Nepal: a cross-sectional study. BMC Med Educ. 2017;17(1):232. https://doi.org/10.1186/s12909-017-1083-0.

19. Kunwar D, Risal A, Koirala S. Study of depression, anxiety and stress among the medical students in two medical colleges of Nepal. Kathmandu Univ Med J (KUMJ). 2016;14(53):22-6 PMID:27892436.

20. Basnet B, Jaiswal M, Adhikari B, Shyangwa PM. Depression among undergraduate medical students. Kathmandu Univ Med J (KUMJ). 2012; 10(39):56-9. https://doi.org/10.3126/kumj.v10i3.8021.

21. Youssef FF. Medical student stress, burnout and depression in Trinidad and Tobago. Acad Psychiatry. 2016;40(1):69-75. https://doi.org/10.1007/s40596015-0468-9.

22. Maslach C, Jackson SE, Leiter MP. Maslach burnout inventory. 3rd ed. Palo Alto: Consulting Psychologists Press; 1996. URL: https://scholar.google.com/ scholar?q=Maslach+Burnout+Inventory.+3rd+ed.+Palo+Alto,+CA:+ Consulting+Psychologists+Press\%3B+1996\&hl=en\&as_sdt=0\&as_vis=1\&oi= scholart.

23. Maslach C, Schaufeli WB, Leiter MP. Job burnout. AnnuRevPsychol. 2001; 52(1):397-422. https://doi.org/10.1146/annurev.psych.52.1.397.

24. Kristensen TS, Borritz M, Villadsen E, Christensen KB. The Copenhagen burnout inventory: a new tool for the assessment of burnout. Work Stress. 2005;19(3):192-207. https://doi.org/10.1080/02678370500297720.

25. Dyrbye L, Shanafelt T. A narrative review on burnout experienced by medical students and residents. Med Educ. 2016;50(1):132-49. https://doi. org/10.1111/medu.12927.

26. Dyrbye LN, Thomas MR, Huntington JL, Lawson KL, Novotny PJ, Sloan JA, et al. Personal life events and medical student burnout: a multicenter study. Acad Med. 2006;81(4):374-84. https://doi.org/10.1097/00001888-20060400000010.

27. Dyrbye LN, Thomas MR, Massie FS, Power DV, Eacker A, Harper W, et al. Burnout and suicidal ideation among U.S. medical students. Ann Intern Med. 2008;149(5):334-41. https://doi.org/10.7326/0003-4819-149-5200809020-00008.

28. Abdulrahman M, Nair SC, Farooq MM, Al Kharmiri A, Al Marzooqi F, Carrick FR. Burnout and depression among medical residents in the United Arab Emirates: a multicenter study. J Family Med Prim Care. 2018;7(2):435-41. https://doi.org/10.4103/jfmpc.jfmpc_199_17.

29. Fares J, Saadeddin Z, Al Tabosh H, Aridi H, El Mouhayyar C, Koleilat MK, et al. Extracurricular activities associated with stress and burnout in preclinical medical students. J Epidemiol Glob Health. 2016;6(3):177-85. https://doi.org/10.1016/j.jegh.2015.10.003.

30. Mazurkiewicz R, Korenstein D, Fallar R, Ripp J. The prevalence and correlations of medical student burnout in the pre-clinical years: a crosssectional study. Psychol Health Med. 2012;17(2):188-95. https://doi.org/10. 1080/13548506.2011.597770.

31. Santen SA, Holt DB, Kemp JD, Hemphill RR. Burnout in medical students: examining the prevalence and associated factors. South Med J. 2010;103(8): 758-63. https://doi.org/10.1097/SMJ.0b013e3181e6d6d4.

32. Low ZX, Yeo KA, Sharma VK, Leung GK, McIntyre RS, Guerrero A, et al. Prevalence of burnout in medical and surgical residents: a meta-analysis. Int J Environ Res Public Health. 2019;16(9):1479. https://doi.org/10.3390/ ijerph16091479.

33. Tarcan M, Hikmet N, Schooley B, Top M, Tarcan GY. An analysis of the relationship between burnout, socio-demographic and workplace factors and job satisfaction among emergency department health professionals. Appl Nurs Res. 2017:34:40-7. https://doi.org/10.1016/j.apnr.2017.02.011. 
34. Shanafelt TD, Balch CM, Bechamps G, Russell T, Dyrbye L, Satele D, et al. Burnout and medical errors among American surgeons. Ann Surg. 2010; 251(6):995-1000. https://doi.org/10.1097/SLA.0b013e3181bfdab3.

35. Shanafelt TD, Bradley KA, Wipf JE, Back AL. Burnout and self-reported patient care in an internal medicine residency program. Ann Intern Med. 2002;136(5):358-67. https://doi.org/10.7326/0003-4819-136-5-20020305000008.

36. Van der Heijden F, Dillingh G, Bakker A, Prins J. Suicidal thoughts among medical residents with burnout. Arch Suicide Res. 2008;12(4):344-6. https:// doi.org/10.1080/13811110802325349.

37. Govêia CS, da Cruz TTM, de Miranda DB, Guimarães GMN, Ladeira LCA, Tolentino FDÁS, et al. Association between burnout syndrome and anxiety in residents and anesthesiologists of the Federal District. Rev Bras Anestesiol. 2018;68(5):442-6. https://doi.org/10.1016/j.bjan.2018.02.007.

38. Campbell J, Prochazka AV, Yamashita T, Gopal R. Predictors of persistent burnout in internal medicine residents: a prospective cohort study. Acad Med. 2010;85(10):1630-4. https://doi.org/10.1097/ACM.0b013e3181f0c4e7.

39. Thomas NK. Resident burnout. JAMA. 2004;292(23):2880-9. https://doi.org/ 10.1001/jama.292.23.2880.

40. Kumar S. Burnout and doctors: prevalence, prevention and intervention. Healthcare. 2016;4(3). https://doi.org/10.3390/healthcare4030037.

41. Puthran R, Zhang MW, Tam WW, Ho RC. Prevalence of depression amongst medical students: a meta-analysis. Med Educ. 2016;50(4):456-68. https://doi. org/10.1111/medu.12962.

42. Alonso J, Angermeyer MC, Bernert S, Bruffaerts R, Brugha TS, Bryson H, et al. Prevalence of mental disorders in Europe: results from the European study of the epidemiology of mental disorders (ESEMeD) project. Acta Psychiatr Scand. 2004;109:21-7. https://doi.org/10.1111/j.1600-0047.2004.00327.x

43. Kessler RC, Üstün TB. The world mental health (WMH) survey initiative version of the world health organization (WHO) composite international diagnostic interview (CIDI). Int J Methods Psychiatr Res. 2004;13(2):93-121. https://doi.org/10.1002/mpr.168.

44. Steptoe A, Tsuda A, Tanaka Y, Wardle J. Depressive symptoms, socioeconomic background, sense of control, and cultural factors in university students from 23 countries. Int J Behav Med. 2007;14(2):97-107. https://doi. org/10.1007/BF03004175.

45. Rosen IM, Gimotty PA, Shea JA, Bellini LM. Evolution of sleep quantity, sleep deprivation, mood disturbances, empathy, and burnout among interns. Acad Med. 2006;81(1):82-5. https://doi.org/10.1097/00001888-200601000-00020.

46. Talih F, Warakian R, Ajaltouni J, Tamim H. Correlates of depression and burnout among residents in a lebanese academic medical center: a crosssectional study. Acad Psychiatry. 2016;40(1):38-45. https://doi.org/10.1007/ s40596-015-0400-3.

47. Dyrbye LN, Thomas MR, Power DV, Durning S, Moutier C, Massie FS Jr, et al. Burnout and serious thoughts of dropping out of medical school: a multiinstitutional study. Acad Med. 2010;85(1):94-102. https://doi.org/10.1097/ ACM.0b013e3181c46aad.

48. Schonfeld IS, Bianchi R. Burnout and depression: two entities or one? J Clin Psychol. 2016;72(1):22-37. https://doi.org/10.1002/jclp.22229.

49. Tennant C. Work-related stress and depressive disorders. J Psychosom Res. 2001:51(5):697-704. https://doi.org/10.1016/S0022-3999(01)00255-0.

50. Menezes RG, Subba SH, Sathian B, Kharoshah MA, Senthilkumaran S, Pant S, et al. Suicidal ideation among students of a medical college in Western Nepal: a cross-sectional study. Leg Med (Tokyo). 2012;14(4):183-7. https:// doi.org/10.1016/j.legalmed.2012.02.004.

51. Risal A, Manandhar K, Linde M, Koju R, Steiner TJ, Holen A. Reliability and validity of a Nepali-language version of the hospital anxiety and depression scale (HADS). Kathmandu Univ Med J (KUMJ). 2015;13(50):115-24. https:// doi.org/10.3126/kumj.v13i2.16783.

52. Zigmond AS, Snaith RP. The hospital anxiety and depression scale. Acta Psychiatr Scand. 1983;67(6):361-70. https://doi.org/10.1111/j.1600-0447.1983. tb09716.x.

53. Ghosh A, Ghosh T. Modification of Kuppuswamys socioeconomic status scale in context to Nepal. Indian Pediatr. 2009;46(12):1104-5. 20061591.

54. Watson NF, Badr MS, Belenky G, Bliwise DL, Buxton OM, Buysse D, et al. Recommended amount of sleep for a healthy adult: a joint consensus statement of the American Academy of sleep medicine and Sleep Research Society. SLEEP. 2015;38(6):843-4. https://doi.org/10.5664/jcsm.4758.

55. Yusoff MSB, Rahim AFA, Yaacob MJ. The development and validity of the medical student stressor questionnaire (MSSQ). ASEAN J Psychiatry. 2010; 11(1):13-24. https://scholar.google.com/scholar_lookup?journal=ASEAN+
Journal+of+Psychiatry\&title=The+development+and+validity+of+the+ Medical+Student+Stressor+Questionnaire+(MSSQ)\&author=SBY+ Muhamad\&author=FAR+Ahmad\&author $=$ MJ+Yaacob\&volume $=11$ \&publication_year $=2010 \&$ pages $=1-15 \&$.

56. R Core Team. R: a language and environment for statistical computing. Vienna: R Foundation for statistical Computing; 2019. https://www.R-project. org.

57. Warnes GR, Bolker B, Lumley T, Johnson RC. Contributions from Randall C. Johnson are copyright SAIC-Frederick and Inc. funded by the intramural research program and of the $\mathrm{NIH}$ and National Cancer Institute and Center for Cancer Research under NCl contract NO1-CO-12400. Gmodels: various R programming tools for model fitting; 2018. R package version 2.18.1. https://CRAN.R-project.org/package=gmodels.

58. Max Kuhn. Contributions from Jed Wing and Steve Weston and Andre Williams and Chris Keefer and Allan Engelhardt and Tony Cooper and Zachary Mayer and Brenton Kenkel and the R Core Team and Michael Benesty and Reynald Lescarbeau and Andrew Ziem and Luca Scrucca and Yuan Tang and Can Candan and Tyler Hunt. Caret: classification and regression training; 2019. R package version 6.0-8. https://CRAN.R-project. org/package=caret.

59. Tuszynski J. caTools: tools: moving window statistics, GIF, Base64, ROC AUC, etc; 2019. R package version 1.17.1.2. https://CRAN.R-project.org/package= caTools.

60. Mangiafico S. Rcompanion: functions to support extension education program evaluation; 2019. R package version 2.2.1. https://CRAN.R-project. org/package=rcompanion.

61. Zeileis A, Hothorn T. Diagnostic checking in regression relationships. $R$ News. 2002;2(3):7-10 https://CRAN.R-project.org/doc/Rnews/.

62. Sing T, Sander O, Beerenwinkel N, Lengauer T. ROCR: visualizing classifier performance in R. Bioinformatics. 2005;21(20):7881 http://rocr.bioinf.mpi-sb. mpg.de.

63. Hamner B, Frasco M. Metrics: evaluation metrics for machine learning; 2018. R package version 0.1.4. https://CRAN.R-project.org/package=Metrics.

64. Lele SR, Keim JL, Solymos P. ResourceSelection: resource selection (probability) functions for use-availability data; 2019. R package version 0.35. https://CRAN.R-project.org/package=ResourceSelection.

65. Lumley T. Survey: analysis of complex survey samples; 2019. R package version 3.35-1. https://cran.r-project.org/web/packages/survey/index.html.

66. Wei T, Simko V. R package "corrplot": visualization of a correlation matrix (version 0.84); 2017. https://github.com/taiyun/corrplot.

67. Wickham H. ggplot2: elegant graphics for data analysis. New York: SpringerVerlag; 2016. https://ggplot2.tidyverse.org.

68. Fox J, Weisberg S. An $\{R\}$ companion to applied regression. 3rd ed. Thousand Oaks: Sage; 2019. URL: https://socialsciences.mcmaster.ca/jfox/ Books/Companion/.

69. Mata DA, Ramos MA, Bansal N, Khan R, Guille C, Di Angelantonio E, et al. Prevalence of depression and depressive symptoms among resident physicians: a systematic review and meta-analysis. JAMA. 2015;314(22):237383. https://doi.org/10.1001/jama.2015.15845.

70. Frajerman A, Morvan Y, Krebs MO, Gorwood P, Chaumette B. Burnout in medical students before residency: a systematic review and meta-analysis. Eur Psychiatry. 2019;55:36-42. https://doi.org/10.1016/j.eurpsy.2018.08.006.

71. Kebede MA, Anbessie B, Ayano G. Prevalence and predictors of depression and anxiety among medical students in Addis Ababa, Ethiopia. Int J Ment Health Syst. 2019;13(1):30. https://doi.org/10.1186/s13033-019-0287-6.

72. Kaufman DM, Day V, Mensink D. Stressors in Ist-year medical school: comparison of a conventional and problem-based curriculum. 1996:8(4): 188-94. https://doi.org/10.1080/10401339609539796.

73. Kaufman DM, Mensink D, Day VJT. Medicine li. Stressors in medical school: relation to curriculum format and year of study. Teach Learn Med. 1998; 10(3):138-44. https://doi.org/10.1207/S15328015TLM1003_3.

74. Sidana S, Kishore J, Ghosh V, Gulati D, Jiloha R, Anand T. Prevalence of depression in students of a medical college in New Delhi: a cross-sectional study. Australas Med J. 2012;5(5):247-50. https://pubmed.ncbi.nlm.nih gov/22848319/.

75. Yusoff MS, Rahim AF. The medical student stressor questionnaire (MSSO) manual. Kota Bharu: KKMED Publications; 2010. https://scholar.google.com/ scholar?cluster $=11384765346336925120 \& h \mid=e n \& a s \_s d t=0,5$. [Accessed 11 Aug 2019]. 
76. Choo CC, Harris KM, Ho RC. Prediction of lethality in suicide attempts: gender matters. Omega (Westport). 2017. https://doi.org/10.1177/ 0030222817725182.

77. Schwenk TL, Davis L, Wimsatt LA. Depression, stigma, and suicidal ideation in medical students. JAMA. 2010;304(11):1181-90. https://doi.org/10.1001/ jama.2010.1300

78. Iqbal S, Gupta S, Venkatarao E. Stress, anxiety \& depression among medical undergraduate students \& their socio-demographic correlates. Indian J Med Res. 2015;141(3):354-7. 25963497.

79. Goebert D, Thompson D, Takeshita J, Beach C, Bryson P, Ephgrave K, et al. Depressive symptoms in medical students and residents: a multischool study. Acad Med. 2009;84(2):236-41. https://doi.org/10.1097/ACM. Ob013e31819391bb.

80. Clark DC, Zeldow PB. Vicissitudes of depressed mood during four years of medical school. JAMA. 1988;260(17):2521-8. https://doi.org/10.1001/jama. 1988.03410170069036

81. Shapiro SL, Shapiro DE, Schwartz GE. Stress management in medical education: a review of the literature. Acad Med. 2000;75(7):748-59. https:// doi.org/10.1097/00001888-200007000-00023.

82. Slavin SJ, Schindler DL, Chibnall JT. Medical student mental health 3.0: improving student wellness through curricular changes. Acad Med. 2014; 89(4):573. https://doi.org/10.1097/ACM.0000000000000166.

83. Buysse DJ, Reynolds CF III, Monk TH, Berman SR, Kupfer DJ. The Pittsburgh sleep quality index: a new instrument for psychiatric practice and research. Psychiatry Res. 1989;28(2):193-213. https://doi.org/10.1016/01651781(89)90047-4

84. Lemma S, Gelaye B, Berhane Y, Worku A, Williams MA. Sleep quality and its psychological correlates among university students in Ethiopia: a crosssectional study. BMC Psychiatry. 2012;12(1):237. https://doi.org/10.1186/ 1471-244X-12-237.

85. Lawson HJ, Wellens-Mensah JT, Attah NS. Evaluation of sleep patterns and self-reported academic performance among medical students at the University of Ghana School of medicine and dentistry. Sleep Disorders. 2019;2019. https://doi.org/10.1155/2019/1278579.

86. De Moor MH, Beem A, Stubbe JH, Boomsma DI, De Geus EJ. Regular exercise, anxiety, depression and personality: a population-based study. Prev Med. 2006;42(4):273-9. https://doi.org/10.1016/j.ypmed.2005.12.002.

87. Broman-Fulks JJ, Berman ME, Rabian BA, Webster MJ. Effects of aerobic exercise on anxiety sensitivity. Behav Res Ther. 2004;42(2):125-36. https:// doi.org/10.1016/50005-7967(03)00103-7.

88. Cnaan RA, Goldberg-Glen RS. Measuring motivation to volunteer in human services. J Appl Behav Sci. 1991;27(3):269-84. https://doi.org/10.1177/ 0021886391273003.

89. Handy F, Cnaan RA, Hustinx L, Kang C, Brudney JL, Haski-Leventhal D, et al. A cross-cultural examination of student volunteering: is it all about résumé building? Nonprofit Volunt Sect Q. 2010;39(3):498-523. https://doi.org/10. 1177/0899764009344353.

90. Almalki SA, Almojali Al, Alothman AS, Masuadi EM, Alaqeel MK. Burnout and its association with extracurricular activities among medical students in Saudi Arabia. Int J Med Educ. 2017;8:144-50. https://doi.org/10.5116/ijme. 58e3.ca8a.

91. Muzafar Y, Khan HH, Ashraf H, Hussain W, Sajid H, Tahir M, et al. Burnout and its associated factors in medical students of Lahore, Pakistan. Cureus. 2015;7(11). https://doi.org/10.7759/cureus.390.

92. Martini S, Arfken CL, Churchill A, Balon R. Burnout comparison among residents in different medical specialties. Acad Psychiatry. 2004;28(3):240-2. https://doi.org/10.1176/appi.ap.28.3.240.

93. Tzischinsky O, Zohar D, Epstein R, Chillag N, Lavie P. Daily and yearly burnout symptoms in Israeli shift work residents. J Hum Ergol (Tokyo). 2001; 30(1-2):357-62. https://doi.org/10.11183/jhe1972.30.357.

94. Chunming WM, Harrison R, Maclntyre R, Travaglia J, Balasooriya C. Burnout in medical students: a systematic review of experiences in Chinese medical schools. BMC Med Educ. 2017;17(1):217. https://doi.org/10.1186/s12909-017-1064-3.

95. Michels PJ, Probst JC, Godenick MT, Palesch Y. Anxiety and anger among family practice residents: a South Carolina family practice research consortium study. Acad Med. 2003;78(1):69-79. https://doi.org/10.1097/ 00001888-200301000-00013.

96. Siu C, Yuen SK, Cheung A. Burnout among public doctors in Hong Kong: cross-sectional survey. Hong Kong Med J. 2012;18(3):186-92. 22665681.

97. Temple J. Resident duty hours around the globe: where are we now? BMC Med Educ. 2014;14(1):S8. https://doi.org/10.1186/1472-6920-14-S1-S8.
98. Nasca. Summary of Changes to ACGME Common Program Requirements Section VI [Available from: http://www.acgme.org/Portals/0/PDFs/NascaCommunity/Section-VI-Memo-3-10-17.pdf. [Accessed 10 Aug 2019].

99. Ripp J, Babyatsky M, Fallar R, Bazari H, Bellini L, Kapadia C, et al. The incidence and predictors of job burnout in first-year internal medicine residents: a five-institution study. Acad Med. 2011;86(10):1304-10. https:// doi.org/10.1097/ACM.0b013e31822c1236.

100. Biaggi P, Peter S, Ulich E. Stressors, emotional exhaustion and aversion to patients in residents and chief residents-what can be done? Swiss Med Wkly. 2003;133(23-24):339-46. https://pubmed.ncbi.nlm.nih.gov/12923685/.

101. Ogawa R, Seo E, Maeno T, Ito M, Sanuki M, Maeno T. The relationship between long working hours and depression among first-year residents in Japan. BMC Med Educ. 2018;18(1):50. https://doi.org/10.1186/s12909-0181171-9.

102. Rodrigues H, Cobucci R, Oliveira A, Cabral JV, Medeiros L, Gurgel K, et al Burnout syndrome among medical residents: a systematic review and metaanalysis. PLoS One. 2018;13(11):e0206840. https://doi.org/10.1371/journal. pone.0206840

103. van Venrooij LT, Barnhoorn PC, Giltay EJ, van Noorden MS. Burnout, depression and anxiety in preclinical medical students: a cross-sectional survey. Int J Adolesc Med Health. 2015;29(3). https://doi.org/10.1515/ijamh2015-0077.

104. Costa EF, Santos SA, Santos AT, Melo EV, Andrade TM. Burnout syndrome and associated factors among medical students: a cross-sectional study. Clinics (Sao Paulo). 2012;67(6):573-80. https://doi.org/10.6061/clinics/ 2012(06)05.

\section{Publisher's Note}

Springer Nature remains neutral with regard to jurisdictional claims in published maps and institutional affiliations.

Ready to submit your research? Choose BMC and benefit from:

- fast, convenient online submission

- thorough peer review by experienced researchers in your field

- rapid publication on acceptance

- support for research data, including large and complex data types

- gold Open Access which fosters wider collaboration and increased citations

- maximum visibility for your research: over $100 \mathrm{M}$ website views per year

At BMC, research is always in progress.

Learn more biomedcentral.com/submissions 